\title{
The Pitfalls of Qualified Moral Veganism. A Critique of Jan Deckers' Holistic Health Approach to Animal Ethics
}

Published in the Journal of Evaluation in Clinical Practice, 2017;1-5. DOI: 10.1111/jep.12786

\author{
Eze Paez
}

\author{
Centre for Ethics, Politics and Society \\ University of Minho \\ joseezequiel.paez@upf.edu
}

\begin{abstract}
:
I critically examine Jan Deckers' position in Animal (De)liberation, where he defends two main views. The first is 'qualified moral veganism': most humans have a duty to abstain from consuming animal products, even if there are circumstances in which doing so is justified. The author argues, on the one hand, from a pan-sentientist view which attributes sentience to all elementary entities and their compounds. Thus, all living things (such as animals and plants) have a capacity for positive and negative experiences. On the other hand, he develops a consequentialist view which assigns moral agents the unconditional duty to promote their own 'holistic health'. This is partly constituted by the agent's 'moral health', that is, her acting in a morally justified way. On Deckers' view, moral agents must care for the health of all living entities; give greater weight to the interests of organisms to which they are more closely biologically related; and respect the integrity of nature. Diets containing animal products have a very high negative health impact, because of how they affect the environment, human food security and the well-being of nonhuman animals. In addition, even though plants are sentient, they are likely less so than animals and their interests must be given less weight. Therefore, most humans should shift to a vegan diet. Decker's second proposal is that a qualified ban on the consumption of animal products should be enacted. After discarding other alternative strategies, Deckers defends its feasibility relying on data obtained via a series of surveys. Though the argument partly succeeds in developing a coherent account accommodating the author's intuitions, I conclude that his ontological and normative frameworks remain too underdeveloped, his appeal to biological relatedness has implausible implications and the methodology he employs in defence of his political position is problematic.
\end{abstract}

\section{Keywords:}

animal ethics; holistic health; Jan Deckers; pan-sentientism; speciesism; veganism 


\section{Introduction}

Animal ethics is an increasingly important area in philosophy. Since it was first introduced in earnest in the contemporary philosophical discussion by Peter Singer during the 1970s, it has grown both in sophistication and in number of practitioners. Its importance has resided in its capacity to challenge moral anthropocentrism. That is, the traditional assumption that only human beings matter when deciding ethically — or that, in any case, humans are vastly more important than other sentient individuals. Taking seriously this challenge requires us to revise our moral and political theories so as to somehow account for nonhuman animals. It also requires us in our everyday lives to consider the impact of our choices on animals, including decisions on what we buy for food or clothing, what sorts of public policies on their behalf we should support and to what extent our altruistic efforts should be devoted to ending their exploitation or otherwise helping them.

A new book by Jan Deckers [1] has made a novel contribution to this field. In it Deckers defends two main claims —one in applied normative ethics, another one in political philosophy. The first is the position he calls 'qualified moral veganism'. In our current circumstances, all things considered, most human beings have a moral duty to "abstain from the consumption of substances that are part of, or have been created by, animals, with the exception of human milk and honey" (p.2). Thus, there might be particular situations in which non-vegan acts of consumption are justified, for instance, because human health might be otherwise jeopardised. But the author argues that it is in fact true for most present humans in most circumstances that such consumption of animal products is wrong. The second claim defended in the book is that a qualified ban on the consumption of animal products is both feasible and morally justified, as well as a more effective strategy than its alternatives to promote the universal practice of qualified moral veganism.

\section{Qualified Moral Veganism}

Though the view that most humans should adopt veganism has been advanced before, the author argues for them in a novel way. Drawing upon some of his previous work [2][3][4], Deckers advances an axiology centred on the notion of "holistic health" and endorses a consequentialist theory which assigns moral agents the aim of promoting their holistic health in certain ways. Here 'holistic health' includes, besides health narrowly conceived and subjective well-being, what Jan Deckers calls "moral health". It consists in "cultivating the right virtues, values and attitudes 
without which it would not be possible to act morally". This implies that "to fulfil their holistic health care duties" (p.6), moral agents must take into account how a decision may affect the health (holistically conceived) of all biological organisms. In order to measure the impact of alternative choices, Deckers employs Global Health Impact units, or GHIs. Agents must "act in ways that maximise positive GHIs" or "minimise negative GHIs", formulations which the author considers interchangeable. Thus, he argues, "[t]he relative wrongness of an action is $[\ldots]$ determined by the degree to which its negative GHIs exceed the smallest quantity of negative GHIs that might be produced by the action that fulfils one's duty" (p.7).

Regarding some of the attitudes which compose moral health, according to Deckers there are five particularly relevant to the ethics of consuming animal products. First, moral agents must treat the well-being or health of all biological entities similarly, as it is prescribed by the traditional principle of equal consideration of interests. Yet, as explained in section 2.9, having the right moral attitudes (or, as Jan Deckers also calls them, 'interests', since they contribute to our holistic health) towards biological entities involves, as well, giving greater importance to the interests of those with which the agent is more closely related biologically. Thus, we ought to be more concerned with the health of fellow members of our species than with that of members of other species (the speciesist interest); more concerned with the health of animals than with that of other biological entities (the animalist interest); and more concerned with the health of an entity, animal or not, the closest it is to us from an evolutionary standpoint (the evolutionist interest). Finally (section 2.11), agents must respect the integrity of nature, which involves a prima facie duty to abstain from affecting the selfdirected goals of other organisms.

On Jan Deckers' view, our qualified duty to embrace veganism stems from considering the overall negative impact which the consumption of animal products has on human health (Chapter 1) and the health of nonhuman animals (Chapter 2). Regarding the former, the book provides readers with a commendably thorough overview of the facts about the environmental impact of animal agriculture, as opposed to plant agriculture, as well as about its effects on human food security. Deckers concludes that, even if any negative GHIs associated with the human treatment of the nonhuman world are ignored, "in many eco-social settings, diets that include animal products produce more negative GHIs than vegan diets" (p.50). Moreover, as argued at length in the Appendix, a vegan diet is nutritionally adequate and may be nutritionally healthier than a non-vegan one. Thus, even if only a narrow definition of human health were considered whereby all human 
duties towards nonhuman organisms are disregarded, there is a good case for qualified moral veganism. Subsequently, the author deals with the impact of non-vegan consumption on nonhuman animals, as well as on the moral health of human agents. Here Deckers starts by describing the harms nonhuman animals suffer under exploitation. Since minimising GHIs requires us, among other things, to inflict as little suffering as possible, we ought to avoid promoting animal agriculture. At least, we must avoid it in those cases in which it is more harmful to nonhumans than plant agriculture — which, admittedly, also causes many nonhumans (such as invertebrates and small vertebrates) to suffer and die, albeit unintentionally so.

When discussing the harms of animal agriculture to nonhumans, Jan Deckers delivers another major exposition of his theoretical framework - namely, his views on philosophy of mind. He adheres to the view he calls pan-sentientism, which he attributes originally to Alfred North Whitehead [5], and which claims that "all simple and [...] 'compound' individuals (as opposed to aggregates such as stones) possess mental or experiential capacities", even if "the degrees to which they have such capacities may vary with entities' (sic) relative material complexities" (p.70). Thus, all elementary particles in the true account of physics, as well as their compounds, such as molecules, unicellular and multicellular organisms, are to some extent sentient. On the one hand, this solves the problem of having to determine which animals are sentient and which are not. All animals are. On the other hand, it turns out that, for instance, plants or fungi are sentient as well, so that they have a wellbeing of their own we ought to care about. It is worth stressing that the author does not purport to justify his position on plant sentience by appeal to scientific literature, even though he does reference some research about sensitivity in plants [6]. His defence of the sentience of plants and other non-animals organisms is entirely based on his pan-sentientist view. Nevertheless, the author is confident that these other organisms have a lower degree of sentience than nonhuman animals. In addition, we ought to care more about the latter because of our animalist interest. Thus he concludes that, on balance, in most circumstances we minimise negative GHIs on other biological organisms if we consume a plant-based diet rather than its alternative.

It is precisely the regard we ought to have for our animalist interest that sets professor Deckers' account of the morality of killing animals apart from other such accounts in the animal ethics literature. Most other accounts — such as those of Alasdair Cochrane [7] and Peter Singer [8], which the author expressly tackles - claim that our reasons against consuming a sentient nonhuman are given by the fact that their interest in living would thereby be frustrated. This implies that we would 
not have reasons of this sort against consuming animals in circumstances in which no nonhuman individual would be harmed. This might happen, for instance, when the animal has already been killed in an accident or by some natural cause. We may have reasons not to consume animal products on these cases because doing so may expectably reinforce our disposition to eat animal flesh in circumstances in which animals would be harmed. We may also have reasons against it because of its possible negative effect on others who see us, and who may thereby become more disposed to consume animals. Yet, in cases where no such bad consequences are expectable, it would be perfectly fine to consume these products. The same follows for human corpses, in cases when we are confident, first, that nobody's feelings would be hurt in the process and, second, that anticipation of such possibility would not cause distress in human beings while still alive.

On Deckers' account, however, we have reasons against consuming nonhuman (and human) flesh in these cases too. Our animalist interest (or our speciesist interest in the case of human flesh) requires regarding human and nonhuman bodies as unsuitable objects for consumption. This is because of the sympathy that agents must have for these entities as fellow members of their species, or as fellow animals. Thus, in many situations, people should abstain from the consumption of animal products, however obtained, and not merely of those obtained through the exploitation of animals. The author argues, however, that in vitro flesh constitutes an exception (section 2.11). Admittedly, producing it involves a degree of disrespect for the integrity of nature, since we are artificially producing animal tissue. Also, consuming it involves a disregard of our animalist interest, since it involves accepting that animal flesh is a proper object for consumption. Yet, all things considered, it is justified to promote the production and consumption of in vitro flesh as an alternative to animal products obtained through traditional exploitative means, provided that its widespread use can prevent enough harms to nonhuman animals.

The final two chapters explore how "the vegan project" (i.e., the political implementation of qualified moral veganism) might be carried out. The author considers two alternative strategies before opting for a qualified ban on the consumption of animal products. The first strategy involves educating people on the moral reasons to adopt qualified moral veganism (p.108-111). One drawback of this strategy, according to Deckers, is that the existence of unequal educational opportunities may lead to higher health inequalities among people. More importantly for its success, individuals whose values are very different from those underpinning qualified moral veganism are likely to abstain from adopting it. Furthermore, these omnivores would keep generating negative 
GHIs affecting even those who decide to adopt a vegan diet. The second strategy involves increasing the costs of animal products by taxing them and providing subsidies to suitable alternatives (p.111-114). On the one hand, the author worries that this strategy is likely to be unfeasible. International cooperation would be needed to ensure that all major countries adopt such a policy. Also, it could not be adopted in societies which place no value on money. On the other hand, the author objects to it on moral grounds, rejecting the view that our moral duty not to consume animal products may be dissolved in exchange for money. Deckers, however, considers that implementing a qualified ban on the consumption of animal products (a prohibition covering only those cases where it is morally wrong) avoids or reduces the aforementioned problems. Such a ban, the author argues, would be justified even if we only considered human health, since human beings cannot exist in good health, in the holistic sense employed in the book, unless they fulfil their duties towards nonhuman animals.

After explaining how the ban would not undermine human food security or alienate humans further from nature (p.122-128), most of the argument (Chapter 3, p.114-118; Chapter 4) is devoted to answering the objection that the ban cannot succeed in a democratic community. The reason for this is that allegedly most people would not be persuaded to embrace it. The author presents as evidence to the contrary the results of a series of "deliberative exchanges" with six academic scientists working on issues related to environmental science at Newcastle University; twenty-one philosophy students of the same university who had taken a module on environmental ethics; six randomly selected individuals from the Newcastle area and six workers from a slaughterhouse in Oldham. After evaluating the evidence, professor Deckers concludes, first, that there seems to be no relevant consideration that he may have overlooked in his argument which may give us reasons against qualified moral veganism. Second, he identifies a widespread belief that it is objectionable to inflict pain on animals and to kill them in order to consume products derived from them. Thus, individuals such as the ones interviewed should be ready to embrace the vegan project, "provided that they are willing to be consistent" (p.129).

\section{Problems in Deckers' View}

Jan Deckers' proposal is both original and ambitious. Because of that, his views would have benefited extensively from a larger treatment. His holistic health consequentialism, as well as his GHIs-based metric, perform most of the argumentative work. Unfortunately, there is not enough 
space devoted to them in the book, so that they remain insufficiently developed. That impairs the reader's capacity to comprehend and follow the argument without major difficulties. This is compounded by the author's tendency to employ his own, non-standard terminology to refer to common philosophical concepts. For instance, it is apparent after careful reading that the term 'holistic health' is equivalent to 'flourishing' or 'eudaemonia'. Thus, 'health in a narrow sense' corresponds to the ordinary use of the term, whereas 'moral health' refers to 'virtue'. Part of the eudaemonic existence consists in enjoying life; part of it consists in acting morally (p.10). A virtuous agent recognises as her ultimate (agent-relative) aim the promotion of her eudaemonia. That entails minimising the negative impact of her decisions on the possibilities for flourishing of all other organisms. As stated, the author explained his positions in detail in previous works. Yet, given their importance, they should have been elaborated in the book itself to facilitate analysis. A similar problem bedevils his endorsement of pan-sentientism. The claim that elementary particles and non-animal living organisms are sentient is but one position among others in the philosophy of mind, and one that many may find counterintuitive. Greater space ought to have been devoted to argue how it is at least as plausible as the claim that only organisms with certain complex functional structures (such as central nervous systems) are sentient.

It is clear that using pan-sentientism as an element in his argument makes Jan Deckers' task more difficult than it need be. Yet, in addition, it creates ulterior problems. His aim is to advocate for a position that includes non-animal organisms in dietary choices, even after claiming that all living entities are sentient. Thus, he is forced to show how consuming some (non-animal) sentient organisms is justified, whereas consuming others (animals) is not. Moreover, he must do so without any method to determine whether the sentience of non-animals is inferior to that of animals. He simply assumes that is the case. Therefore, so as to strengthen his position, he needs to appeal to our speciesist, animalist and evolutionist interests to justify giving greater weight to the interests of human and nonhuman animals than to those of, e.g., plants.

Yet an appeal to such interests begs the question of why we should consider that biological relatedness matters in a way that allows us to care less for the similar interests of those less related to us. First, this runs contrary to the dominant view in the animal ethics literature that mere speciesmembership is irrelevant for moral consideration. On Jan Deckers' account, contrariwise, agents act wrongly when they do not give greater weight to the interests of their species co-members. In view of the arguments against species-based discrimination which have been produced in the last 
decades, however, the author should have engaged in a discussion with them so as to show that, nevertheless, some kinds of speciesism are justified.

Second, acting on these interests seems to have unacceptable consequences in some cases. One such implication which the author himself considers is that we ought to care more for the interests of those belonging to our race, given our closer relatedness. One may think that this amounts to a legitimisation of racism. His retort is that, on balance, we humans have to grant equal moral significance to all members of our species, in spite of racial differences. This is because he believes that: (i) we are moral agents that object to being racially discriminated and who object to non-moral agents of our race being discriminated as well; and (ii) a world in which there is reciprocal racial discrimination seems worse than one where there is none (p.82). Given these facts, GHIs are maximised if we choose to disregard whatever interest we may have in preferring those of our own race over those of others. Nevertheless, this is an implicit acknowledgement that there is such a racist interest. It just so happens that because race-based discrimination, and the resentment thereof, can be reciprocal, it is better if we all follow a strict rule not to act on our racist interests. Thus, it seems that, on his view, there are reasons to give greater weight to members of our own race, even if, all things considered, we must not act upon them.

Another seemingly unacceptable implication has to do with the speciesist interest. Imagine some extraterrestrial rational agents that started to interact with humans, or some artificial agent engineered by humans themselves. Just as human beings must give lesser weight to the interests of nonhuman sentient beings, so must non-human rational agents discount human interests. This is compatible, as before, with an all-things-considered duty to act as if both human and nonhuman interests were of equal weight, given the harms which may ensue from reciprocal discrimination. Yet suppose that those extraterrestrial beings, or that artificial intelligence, were so vastly superior to us that human ability to resist being discriminated by them and to reciprocate was similar to that many nonhumans possess in the actual world. It seems that, on Deckers' account, it might be justified for these nonhuman rational agents to act on their speciesist interest and care less for the well-being of humans. What this discussion also shows is that speciesism against nonhuman animals is justified in practice simply because these nonhumans cannot object to being discriminated, resent it or reciprocate. 
This constitutes an indirect appeal to some psychological capacities the typical human has, and which nonhumans allegedly lack, to justify a partial disregard of their interests. Nevertheless, it is false that all humans possess these capacities. On Jan Deckers's view this implies that, if no rational agent cares for these individuals, it may be justified to act on our racist or speciesist interests against them. That seems implausible. Contrariwise, since some members of other races or other rational species would be deeply cared for by some rational agents, others would not be justified in disregarding their interests. Furthermore, the author's argument against acting on our racist or speciesist interests turns on the victim's capacities to understand existing discrimination, rebel against it and repay in kind. Thus, if nonhuman animals were uplifted and gained the ability to object to being discriminated and to reciprocate by discriminating against humans, it would become wrong to act on our speciesist attitudes.

A final implication is that we may have to discount more the interests of living organisms that, given their structure, could be assumed to have weightier interests than others, simply because we are more closely related to the latter than to the former. For instance, we ought to discount the interests of an oak tree more than those of a protozoon. Whether the results of this are implausible or not would depend on how considerable an interest of a certain organism is after the discount has been applied. It may be that the closer, weaker interests of the protozoon count more than the farther, weightier interests of the oak tree. It may be otherwise. It remains unknown, since the author does not provide us with the mechanics of this operation.

An independent problem lies in Jan Deckers's view that our speciesist and animalist interests require us not to regard human or animal corpses as proper objects of consumption. It is not entirely clear, but it seems that on his ontological position, deceased organisms should not be viewed as compounds with their own sentience, or flourishing, whose self-directed goals our intervention may frustrate. Indeed, they cannot be viewed as compounds at all. After death, they are just mere aggregates of cells arranged in a certain way, and no longer multicellular animals of any kind. If virtuous action consists in part in a certain respect for animals of all kinds, it cannot directly entail abstaining from the consumption of their remains, since those no longer qualify as animals, human or otherwise. Of course, we may make a case for the indirect relevance of avoiding such consumption, as explained above. Yet that is precisely the path which the author chooses not to follow. Maybe a more robust theoretical account of the importance of biological relatedness for 
moral consideration, as Deckers understands it, would have contributed to the plausibility of these claims (and the implications just reviewed) for those who do not immediately share his intuitions.

Finally, his argument for the qualified ban of animal products appears to be methodologically problematic. So as to prove that it is a possible strategy and, given other considerations, superior to its alternatives, Deckers correctly appeals to evidence regarding people's attitudes on the matter. Nevertheless, given the nature of the evaluation method he employs and the sample of people surveyed, the results seem unsuitable for generalisation. What individuals with some training in environmental science or ethics, and slaughterhouse workers, may believe need not be representative of the beliefs of the average citizen, of which only six were included. Moreover, that is too small a number to allow for extrapolation, so as to estimate the attitudes of a whole country (such as the UK) or a wider cultural region. The deliberative exchanges that constitute the book's last chapter are extremely interesting in themselves, and in the category of evidence needed for the author's argument. They are, though, insufficient for his purposes.

\section{Conclusion}

Jan Deckers's philosophical view is strikingly distinct from that of other contemporary animal ethicists. From a metaphysical point of view, his defence of pan-sentientism is rare, if not unique. From an ethical standpoint, his axiological and normative views are also very different from more mainstream positions, as well as more complex. Like Peter Singer, but unlike Alasdair Cochrane or Tom Regan [9], he rejects a deontological approach in favour of a consequentialist one. But unlike Singer, he rejects a purely welfarist axiology. Instead, he posits the flourishing of each moral agent as her supreme aim of action, but understands it not only in terms of subjective well-being, but also as virtuous behaviour. His understanding of virtue is, again, peculiar, by defending a disposition to care more for the entities more biologically related to us and a disposition to respect the integrity of nature. The resulting view is not that we ought to adopt veganism because an omnivore diet violates deontological side-constrains that protect the interests of animals. Nor that we ought to do it because that maximises expected utility. It is because living on a vegan diet maximises our flourishing. Even if it is harmful to plants, the harms otherwise inflicted on nonhuman animals are presumably more severe and should matter more to us, because they are our closest relatives. 
As argued, however, his metaphysical and normative views are too underdeveloped. In addition, his insistence on the importance of biological relatedness seems to have implausible implications. Thus, it entails the existence of a racist interest (even if, all things considered, it should not be acted upon), as well as the general justifiability of caring less for the well-being of those biologically farther from us who cannot successfully object to being discriminated and rebel against it. It also entails that the flourishing of some unicellular organisms (protozoa) should be more important to us than those of plants (oak trees), simply because they are phylogenetically closer to us.

Surely, there are those who, intuitively or on reflection, accept the author's broader normative views, such as his eudaemonistic consequentialism, the relevance of biological relatedness to moral consideration and the importance of the integrity of nature. Certainly, some endorse his position on sentience. In that respect, this book attempts to elaborate the best argument for veganism that can accommodate such beliefs. It succeeds in many respects. Yet, overall, a more robust defence is possible. Undoubtedly it could have been produced in this book, if only it had been granted more room for development. I am looking forward to the ways in which Jan Deckers will refine, complete and strengthen his position in the years to come.

\section{References}

1. Deckers J. Animal (De)liberation: Should the Consumption of Animal Products be Banned. London: Ubiquity Press; 2016.

2. Deckers J. What policy should be adopted to curtail the negative global health impacts associated with the consumption of farmed animal products? Res Publica. 2010;16 (1): 57-72.

3. Deckers J. Negative 'GHIs', the right to health protection, and future generations. Journal of Bioethical Inquiry. 2011; 8 (2): 165-76.

4. Deckers J. In defence of the vegan project. Journal of Bioethical Inquiry. 201310 (2):187-95. 
5. Whitehead A. Process and Reality. An Essay in Cosmology (Corrected Edition by David Griffin and Donald Sherburne). New York, NY: The Free Press; 1978.

6. Baluška F., Mancuso S., Volkmann D. \& Barlow P. W. The "root-brain” hypothesis of Charles and Francis Darwin: Revival after more than 125 years. Plant Signaling \& Behavior. 20094 (12): 1121-1127.

7. Cochrane A. Animal rights without liberation. Applied ethics and human obligations. New York, NY: Columbia University Press; 2012.

8. Singer P. Animal Liberation. London: Vintage Digital; 2015 [1975].

9. Regan T. The Case for Animal Rights. Berkeley, California: University of California Press; 2004 [1983]. 